\title{
Supply And Demand Structure Non-equilibrium Model of City Agglomeration Transportation System
}

\author{
WEI Lei ${ }^{1, \text { a }}$, GAO Wei ${ }^{2, b}$, LI Cheng-bing ${ }^{2, c}$ \\ ${ }^{1}$ School of Transportation Science and Engineering, BUAA, Beijing, 100000, China \\ ${ }^{2}$ School of Transportation, Inner Mongolia University, Hohhot Inner Mongolia, 01007, China \\ aemail: 1051954343@qq.com, bemail: 981749142@qq.com, cemail: 739875282@qq.com
}

\begin{abstract}
Keywords: integrated transportation; non-equilibrium model; traffic supply and demand; supply and demand structure; city agglomeration; co-ordination of supply and demand

Abstract: In view of the disequilibrium problem of city agglomeration transport supply and demand, structure non-equilibrium model of transport supply and demand was put forward considering the mutual feed mechanism of transport supply and demand structure. Firstly, based on a clear definition of scope to city agglomeration and transport supply and demand structure of city agglomeration, the issue of structure disequilibrium of city agglomeration transport supply and demand was proposed. Secondly, according to the mutual feed mechanism of transport supply and demand, system dynamic principles was used to build structure disequilibrium model after studying the computation method of transport supply and transport demand of each traffic modes. Finally, the theory of stability of differential equation was used to solve this model and equilibrium proportion of city agglomeration transport supply was concluded. An instance of HuBaoOr city agglomeration was given to verify the scientific nature of the model.
\end{abstract}

\section{Introduction}

As the basic support of agglomeration development, agglomeration traffic should maintain a balanced structure of supply and demand while balancing the total value. However, the lacking of unified planning and effective coordination mechanism lades transportation supply and demand structure no-equilibrium more and more prominent which causes many traffic problems and hinder the development of agglomeration. Therefore, the study of supply and demand structure non-equilibrium is meaningful.

At present, there have been some related research at home and abroad on the problem. According to the problems of urban traffic resulted from disequilibrium structure of traffic supply and demand, the RACV management strategy was put forward to balance the traffic supply and demand [1]. Transportation supply and demand interaction differential equations are set up by Wei Jun[2]. Yuan Jing, etc. analyzed the influencing factors of freight demand structure and supply structure, built the evaluation model for the adaptation and put forward the adaptability evaluation standard using the information entropy theory[3]. The disequilibrium model of total supply and demand of city agglomerations transportation system is constructed by differential dynamics [4]. Qian Hanfeng, etc. points out that the traffic supply and traffic demand are balanced on the total amount, and the structure and function are closely coupled is the optimal state of city traffic[5]. Pei $\mathrm{Wu}$ studied the road network characteristics of city agglomeration with some quantitative methods, such as the traffic assignment algorithm based on the path, the design algorithm of the integrated hybrid road network[6] and so on.

Most of domestic and abroad researches about transport supply and demand structure have been based on a single city little from the city agglomeration perspective. The few studies about city agglomeration have focused on only one transport mode very little on transport supply and demand structure. However, in the modern transportation system, city agglomeration has become the carrier and the main unit of international competition ${ }^{[7]}$. Based on this, a supply and demand structure non-equilibrium model of city agglomeration transportation system was built to analyze supply and demand non-equilibrium of transportation structure visually. This method can provide a theoretical 
foundation for realizing reasonable configuration and equilibrium structure of city agglomeration transport resource.

\section{Describing non-equilibrium problems of city agglomeration transport supply and demand structure}

City agglomeration transportation is internal integrity and opening to outside. Therefore, the research includes internal transport supply and demand of a city inside city agglomeration, intercity transport supply and demand within city agglomeration and intercity transport supply and demand between cities within city agglomeration with other cities outside city agglomeration.

Transportation supply and demand structure is the proportion of highway, rail, air and water transportation supply and demand in city agglomeration. As traffic demand tends to exceed traffic supply, the relatively equilibrium state is a kind of dynamic equilibrium structure under the pressure of supply shortage rather than totally same[3]. When four traffic modes form a relatively stable structure of traffic supply to meet traffic demand, supply and demand structure of city agglomeration transportation is equilibrium.

The city agglomeration in our country started late but developed rapidly. There are still many problems in the planning and construction of transportation infrastructure in city agglomeration and many traffic problems are particularly severe. Supply and demand structure of transportation non-equilibrium in China is revealed in the shortage of total transport supply amount and disequilibrium of the transport supply-demand structure partial traffic mode is insufficient, and part of the traffic mode idle capacity problems coexist.

\section{Building supply and demand structure non-equilibrium model of city agglomeration transportation system}

\section{Parameter definition}

(1)Research area should be determined before study city agglomeration transport supply and demand structure equilibrium. The research area consists of two parts: all involved cities in the city agglomeration and other closely neighboring cities. $S=\left\{\mathrm{s}_{q} \mid 1 \leq q \leq n\right\}$ denote the set of cities in the research area. $S^{\prime}=\left\{\mathrm{s}_{p} \mid 1 \leq p \leq m\right\}$ denote the set of cities of selected city agglomeration. It is obvious $S^{\prime} \subset S$.

(2) $\overrightarrow{\boldsymbol{G}}$ is traffic supply structure vector and $\overrightarrow{\boldsymbol{D}}$ is traffic demand structure vector of city agglomeration; $\overrightarrow{\boldsymbol{G}_{\mathrm{j}}}$ is traffic supply structure vector and $\overrightarrow{\boldsymbol{D}_{\mathrm{j}}}$ is traffic demand structure vector between city $S_{i}$ and $S_{j}$.

(3) $G_{(1) \max } 、 G_{(2) \max } 、 G_{(3) \max } 、 G_{(4) \max }$ are maximum supply of highway, rail, air and water transportation as they develop independently, which means $G_{b} \leqslant G_{(\mathrm{b}) \max } ; D_{(1) \max } 、 D_{(2) \max }$ 、 $D_{(3)} \max 、 D_{(4) \max }$ are maximum demand of highway, rail, air and water transportation as they develop independently, which means $D_{\mathrm{b}} \leqslant D_{(\mathbf{b}) \max }$.

\section{Computing traffic supply structure vector and traffic demand structure vector of city agglomeration}

Traffic supply and demand structure vector of every part in city agglomeration at time $t$ should be computed to compute traffic supply and demand structure vector of city agglomeration, that is

$$
\overrightarrow{\boldsymbol{D}_{k}(\mathrm{t})}=\sum_{\mathrm{i}} \sum_{j} \overrightarrow{\boldsymbol{D}_{\mathrm{i}}(\mathrm{t})}
$$




$$
\overrightarrow{\boldsymbol{G}_{k}(\mathrm{t})}=\sum_{\mathrm{i}} \sum_{j} \overrightarrow{\boldsymbol{G}_{i j}(\mathrm{t})}
$$

(1) If $i=j$ and $1 \leq i \leq m, 1 \leq j \leq m, \quad s_{i}=s_{j}$. At this time $\overrightarrow{\boldsymbol{G}_{\mathrm{k}}(\mathrm{t})}, \overrightarrow{\boldsymbol{D}_{k}(\mathrm{t})}$ are traffic supply and demand structure vector of a city in the city agglomeration.

(2) If $i \neq j$ and $1 \leq i \leq m, 1 \leq j \leq m, s_{i} \neq s_{j}, \quad s_{i}, s_{j} \in S^{\prime}$. At this time $\overrightarrow{\boldsymbol{G}_{k}(\mathrm{t})}, \overrightarrow{\boldsymbol{D}_{k}(\mathrm{t})}$ are traffic supply and demand structure vector between city in the city agglomeration.

(3) If $i \neq j$ and $1 \leq i \leq m \leq j \leq n, \quad s_{i} \in S^{\prime}, \quad s_{j} \notin S^{\prime}$ and $s_{j} \in S$. At this time $\overrightarrow{\boldsymbol{G}_{k}(t)}, \overrightarrow{\boldsymbol{D}_{k}(t)}$ are traffic supply and demand structure vector between the city agglomeration and outside.

In conclusion, the traffic demand and supply structure vector of city agglomeration are

$$
\begin{aligned}
& \overrightarrow{\boldsymbol{D} t)}=\sum_{k=1}^{3} \overrightarrow{\boldsymbol{D}_{k}(\mathrm{t})}=\sum_{i} \sum_{j} \overrightarrow{\boldsymbol{D}_{\mathrm{i}}(\mathrm{t})} \\
& \overrightarrow{\boldsymbol{G} \mathrm{t})}=\sum_{k=1}^{3} \overrightarrow{\boldsymbol{G}_{k}(\mathrm{t})}=\sum_{i} \sum_{j} \overrightarrow{\boldsymbol{G}_{i}(\mathrm{t})}
\end{aligned}
$$

\section{Building supply and demand structure non-equilibrium model of city agglomeration transportation system}

City agglomeration transport supply and demand structure have dynamic relation and they influence each other by various interactions. In ideal status, if the growth rate of the structure is zero at a certain moment, it will in stable status, which means it achieve equilibrium. Thus, transport supply and demand structure growth rate can be used to building the non-equilibrium model.

To show the interaction between supply and demand structure, with the study of city agglomeration supply and demand structure in 2.2, differential equation is used to show the interact relationship between traffic supply and demand of transportation form $b$ in time $t$ based on differential dynamic:

$$
\begin{aligned}
\frac{\mathrm{d} D_{b}}{\mathrm{~d} t} & =r(b) D\left(1-\frac{D_{b}}{D_{(b) \max }}+\sigma_{(b) G D} \frac{G_{b}}{G_{(b) \max }}\right) \\
\frac{\mathrm{d} G_{b}}{\mathrm{~d} t} & =r(b) G\left(1-\frac{G_{b}}{G_{(b) \max }}+\sigma_{(b) D G} \frac{D_{b}}{D_{(b) \max }}\right)
\end{aligned}
$$

In this equation, $\frac{\mathrm{d} D_{b}}{\mathrm{~d} t}$ and $\frac{\mathrm{d} G_{b}}{\mathrm{~d} t}$ are traffic demand and supply growth rate at time $t$ of transportation mode $b ; \mathrm{D}_{\mathrm{b}}$ and $\mathrm{G}_{\mathrm{b}}$ are base year demand and supply of transportation mode $b$; $r$ (b) $G$ and $r$ (b) $D$ are inherent growth rate of traffic supply and demand of transportation mode $b$; $\sigma$ (b) GD is the effect of traffic supply on traffic demand and $\sigma$ (b) $D G$ is the effect of traffic demand on traffic supply; $b=1,2,3,4$ as highway, rail, air and water transportation; factor $\left(1-\frac{D_{\mathrm{b}}}{D_{(b) \max }}\right)$ and $\left(1-\frac{D_{\mathrm{b}}}{D_{(b) \max }}\right)$ reflect traffic demand and supply obey Logistic Law and they refer to maximum traffic demand and supply block themselves; $\sigma_{(b) G D} \frac{G b}{G_{(b) \max }}$ and $\sigma_{(b)} D_{b} \frac{D_{b}}{D_{(b) \max }}$ are the promotion of traffic supply to traffic demand and traffic demand to traffic supply.

\section{Solving the model}

With the analysis of part 2.3, in ideal condition, if the change rate of city agglomeration supply and demand structure are 0 city agglomeration supply and demand will be stable. And it is the equilibrium solution of the model. Making equation (5) and (6) equal to zero, result in

$$
\begin{aligned}
& r_{(b) D}\left(1-\frac{D_{b}}{D_{(b) \max }}+\sigma_{(b) G D} \frac{G_{b}}{G_{(b) \max }}\right)=0 \\
& r(b) G\left(1-\frac{G_{b}}{G_{(b) \max }}+\sigma_{(b) D G} \frac{D_{b}}{D_{(b) \max }}\right)=0
\end{aligned}
$$


The equilibrium solution of traffic demand and supply are:

$S_{1}(0,0) 、 S_{2}\left(G_{(i) \max }, 0\right) 、 S_{3}\left(0, D_{(i) \max }\right) 、 S_{4}\left(\frac{D_{(b) \max }\left(1+\sigma_{(b) b 0)}\right.}{1-\sigma_{(b) b \sigma} \sigma_{(b) 06}}, \frac{G_{(b) \max }\left(1+\sigma_{(b) b 6}\right)}{1-\sigma_{(b) b 0} \sigma_{(b) b 6}}\right)$

For transportation mode $b$, at $S_{1}, S_{2}$ and $S_{3}$ some traffic volume are 0 , and they do not conform to reality and serve as unintended solution. So $S_{4}\left(\frac{D(b) \max \left(1+\sigma_{(b) b 0)}\right.}{1-\sigma_{(b) b 0} \sigma_{(b) b 6}}, \frac{G(b) \max \left(1+\sigma_{(b) b \sigma}\right)}{1-\sigma_{(b) b 0} \sigma_{(b) b 6}}\right)$ is the equilibrium solution of transportation $b$.

In the end, the equilibrium structure of city agglomerations transportation, highway, rail, air and water transportation can be obtained according to the equilibrium solution of every city agglomeration transportation mode:

$$
\frac{D_{(1) \max }\left(1+\sigma_{(1) G D}\right)}{1-\sigma_{(1) G D} \sigma_{(1) D G}}: \frac{D_{(2) \max }\left(1+\sigma_{(2) G D}\right)}{1-\sigma_{(2) G D} \sigma_{(2) D G}}: \frac{D_{(3) \max }\left(1+\sigma_{(3) G D}\right)}{1-\sigma_{(3) G D} \sigma_{(3) D G}}: \frac{D_{(4) \max }\left(1+\sigma_{(4) G D}\right)}{1-\sigma_{(4) G D} \sigma_{(4) D G}}
$$

When the supply structure of city agglomerations meets the demand of this proportion the structure of supply and demand is balanced.

\section{Case analysis}

In order to confirm the above method, HuBaoOr city agglomeration is taken as an example to analysis the equilibrium structure of transport supply and demand. HuBaoOr city agglomeration includes three center cities, Hohhot, Baotou and Ordos and three non-center cities, Ulanqab, Byannur and Wuhai.

The supply saturation capacities of this city agglomeration in 10 years were highway 39000 , rail 5 000, air 6 000, and the base year supply were highway 33 522.42, rail 3 942.82, air 5 268.03. And the demand saturation capacities were highway 45 240, rail 5 800, air 6 960, and the base year demand were highway 37466.80 , rail 4 400.76, air 2620.73 . According to the traffic survey data of 2015, the supply of highway and rail were less than demand, so the supply inhibited demand growth, $\sigma_{(1) G D}=-0.20, \sigma_{(2) G D}=-0.23$, and the demand drove supply growth, $\sigma_{(1) D G}=0.15, \sigma_{(2) D G}=0.18$. The supply of air in this city agglomeration was more than demand, so the supply drove demand growth, $\sigma_{(3) D G}=0.25$, demand inhibited supply growth, $\sigma_{(3) D G}=-0.30$. HuBaoOr city agglomeration is located in inland and its water transportation is very few, so we do not consider it.

Computing the equilibrium supply and demand structure of HuBaoOr city agglomeration in 10 years with equation (9)

$$
G_{1}: G_{2}: G_{3}=35137.86: 4723.24: 6000
$$

\section{Conclusions}

(1) The relationship between transportation supply and demand has been described, and the interactive feedback mechanism of transportation supply and demand has been analyzed qualitatively. Then supply and demand equilibrium is a dynamic process has been proved.

(2) Transport supply and demand structure non-equilibrium problem in city agglomeration has been studied. Supply and demand structure non-equilibrium model of city agglomeration transportation system is built to find the balanced proportion of city agglomeration transportation supply and demand structure.

(3) The supply and demand structure non-equilibrium model of city agglomeration transportation system can be applied to most of the general city agglomeration. Based on the available data, the equilibrium solution of city traffic supply and demand structure at any time can be calculated, and the deviation between traffic supply and demand structure and the ideal state of the city agglomerations can be predicted. 


\section{References:}

[1]Sanderson J T, Greenwood I B. Demand management: a motoring organisation's perspective[J].International Transport Conference, 1991,91(4):103-108.

[2]WEI J. Model of dynamic relationship between traffic supply and demand[J]. Journal of Chang' an University (Nature Science Edition),2010, (06):86-89+98.

[3]YUAN Jing. Study on the structure equilibrium of transportation supply and demand[D]. Chang' an University,2007.

[4] LI C B. Supply and demand non-equilibrium model of city agglomeration transportation system $[\mathrm{J}]$. Journal of Transportation Systems Engineering and Information Technology, 2017,(01):47-53.

[5] QIAN H F, YANG M. Discussion on city traffic coupled system based on traffic supply and demand balance[J]. Technology \& Economy in Area of Communications,2010,(02):16-18.

[6] PEI Wu. The study on mixed highway network design for city agglomeration[D]. Changsha university of science and technology,2008.

[7] DING J X, LUO P. Thought on transportation development of China city agglomerations in the new period[J]. Regional Economic Review,2014,(02):106-111.

[8] ZHOU S C. Using correlation analysis to predict conversion turnover[J]. Railway Transit and Economy, 1987,11:6-9. 